Global Conferences Series:

Social Sciences, Education and Humanities (GCSSSEH), Volume 6, 2020

International Conference Fakultas Tarbiyah dan Keguruan Universitas Islam Negeri Imam Bonjol Padang (ICFTKUINIBP) 2020

DOI: https://doi.org/10.32698/icftk406

\title{
Reconstruction of Islamic Higher Education for the 21st Hopes, Challenges, Paradigms, and Roles of Arabic
}

\section{Konstruksi Ulang Lembaga Pendidikan Tinggi Islam untuk Abad 21 Harapan, Tantangan, Paradigma, dan Peran Bahasa Arab}

\author{
Abdul Halim Hanafi ${ }^{a}$, Zainal Asril ${ }^{\text {a }}$ \\ ${ }^{a}$ Universitas Islam Negeri Imam Bonjol, Padang, Indonesia \\ E-mail: ahalimhanafi@gmail.com
}

\begin{abstract}
The aim of writing this paper will describe the problems and challenges facing Islmic institution of higher education and the expectations and strategies to deal accuration. So, the problems are how the posision, condition, standarization, accuration, and protection of Islamic higher education to servics costomers or student in Indonesia and how is learning system and developing science in this age. The method use library research with observasion method to document, discussion, and interview method by experts. The research finding are the 21 st century is the age globalization. It takes to impact on interdepedention, competition, and advances in science, information and commucation tecnology on institution of Islamic higher education. Interdepedention describe the somethink happened in a country correlated with other country. This condition has to change of paradigm at manajement of instituion higher education that the society make it is coorporate has to protecs and the best accuration and quickly servics to costomers. The conclusion are (1) the expectation that Islamic higher education must remain firm lying to the main foundations, the Qur'an and Hadith, and pay attention to and strengthen the teaching of Arabic and must be able to prove the truth of the foundation in human/community life and in addition to (2) Islamic higher educational must enter the official level of quality standards, (3) Islamic higher education make themselves as higher education research that aims to change the real. It can be done from simple ways.
\end{abstract}

Keywords: Higher education, paradigm, role arabic.

\section{PENDAHULUAN}

Pendidikan adalah sesuatu yang utopia, yang diharap-harap untuk dicapainya walaupun sangat banyak kesulitan untuk itu.Namun, pembicaraan dan upaya manusia untuk membangun pendidikan tidak pernah berhenti dan selalu berusaha untuk mencapainya, karena manusia menyadari bahwa pendidikan menyangkut hajat hidup manusia pada masa depannya dan perkembangan peradabannya, kemajuan ilmu, teknologi, ekonomi dan politik. Dengan demikian, pendidikan tidak dapat dipisahkan dari kehidupan manusia yang beradab dan merdeka.(Hassan Langulung, 1996). Peradaban yang terpuji dibangun melalui pendidikan manusia dan memanusiakan manusia.Manusialah yang menjadi sasaran pendidikan, menjadi objek dan sekaligus menjadi subjek pendidikan (homo educandum) agar manusia menjadi hamba Allah dan khalifahNya yang terbaik.Inilah agaknya yang diinginkan oleh sabda Nabi Muhammad SAW yang mengatakan " Innama buistu li utammima makarimal akhlaq, Aku hanya diutus untuk menyempurnakan akhlak yang mulia) dan .Addabaniy rabby fa ahsana ta'dibiy (Tuhanku telah mendidikku, lalu mendidikku secara baik. (Hadis Shahih).

Adalah tepat dan benar yang dirancang dan dibangun oleh para ulama bahwa pelaksanaan pendidikan Islam itu berlandaskan kepada Al-Qur'an dan Hadis Nabi SAW sebagai landasan utamanya serta menjadi sumber filosofi dan inspirasi yang untuk mengamalkannya memerlukan petunjuk dan peraturan teknis dan perundangan berikutnya yang turut menjelaskannya dan membimbing pengambil kebijakan dan pengamalan

Copyright $@ 2020$, the Authors. Published by Redwhite Press. 
petunjuk tersebut. Menyadari hal ini, para ulama zaman klasik menjadikan ilmu dan teknologi sebagai media pengamalan Al-Qur'an dan Sunnah Rasul.Dalam persfektif ini, Islam dan ilmu adalah satu kesatuan yang utuhIslam dapat dianggap sebagai ilmu dan ilmu dapat dianggap sebagai ajaran Islam, sunnatullah.Inilah peradaban Islam yang membuat ummat Islam disegani di dunia, Barat dan Timur.Oleh sebab itu, lembaga pendidikan Islam abad 21 memerlukan paradigma yang tepat dalam pengembangan ilmu dan pembelajarannya.

Pendidikan Tinggi Islam yang terjadi pada masa sekarang berkaitan dengan kebijakan-kebijakan yang telah diputuskan oleh para pemegang kebijakan pada masa lalu, baik oleh lembaga pemerintah, swasta dan masyarakatnya.Namun keadaan masa lalu yang baik belum tentu cocok dan dapat diterapkan pada masa kini, khususnya abad 21.Walaupun masa lalu yang baik dapat menjadi pelajaran untuk menetapkan kebijakan masa kini.Dari sini terlihat bahwa mengambil kebijakan yang tepat untuk lembaga pendidikan tinggi Islam pada masa kini memerlukan paradigma yang tepat, pertimbangan yang luas dan mendasar sehingga tidak mengalami kekeliruan peradaban. Hal ini berarti wajah lembaga pendidikan tinggi Islam abad 21, seperti UIN, IAIN, STAIN, dsb, turut dibentuk oleh pembangunan dan kebijakan pada masa yang lalu yang memerlukan penyesuaian pada masa kini, karena tuntutan zamannya berubah, peradaban dan gaya hidup manusia berubah. Apalagi pendidikan itu memerdekakan manusia; bukan menjajah siswa untuk berbuat harus begini dan begitu. Yang membuat parasiswa/mahasiswa tidak merdeka dalam proses pendidikannya.

Paparan di atas semakin jelas dengan adanya krisis global yang membawa efek kepada krisis ekonomi, sosial, akhlak, politik, dsb. Krisis ini, menurut Azyumardi, tidak hanya menimbulkan keprihatinan mendalam tentang meningkatnya drop-out rate di kalangan mahasiswa, tetapi juga semakin merosotnya efektivitas dan efesiensi pendidikan tinggi dalam menghasilkan daya saing yang handal dan tangguh dalam globalisasi yang penuh tantangan (Azzyumardi Azra,2009). Oleh sebab itu, lembaga pendidikan tinggi Islam harus memantapkan jati dirinya dengan berpegang teguh pada landasan utamanya dan dapat mengembangkan dirinya menjadi pendidikan tinggi yang dapat memberikan competitive advantage kepada mahasiswanya, outcome-nya, dan transparan dan akuntabel dalam manajemennya.

Paparan di atas menimbulkan banyak permasalahan pada lembaga pendidikan Islam, antara lain, apakah lembaga pendidikan Islam abad 21 ini masih konsisten dengan landasan utamanya, Al-Qur'an dan Hadis SAW, dalam menjalankan praktek pendidikannya? Apakah lembaga pendidikan tinggi Islam (LPTI) ingin berbanggabangga dengan masa lalu yang jaya tanpa memperhitungkan keadaan dan tuntutan masyarakat abad kini?apakah perubahan abad membuat LPTI harus berubah total? Bagaimana paradigma LPTI dalam mengembangkan ilmu-ilmunya? Bagaimana tantangan yang dihadapi LPTI?, dan bagaimana alternatif solusinya yang mangkus?

Persoalan yang akan dijawab oleh artikel ini yaitu bagaimana membangun LPTI pada masa kini di Indonesia dan bagaimana paradigma pengembangan ilmu bagi LPTI agar menjadi perguruan tinggi yang berkarakter dan kompetitif? Untuk menjawab persoalan ini, penulis memaparkan beberapa pemikiran yang konstruktif, yaitu memahami kondisi pendidikan tinggi Islam pada abad 21 melalui studi referensi, observasi terhadap kondisi objektif beberapa cara perguruan tinggi mengembangkan ilmunya, pengamatan terhadap pemikiran para pakar tentang LPTI, dan metode analisis kritik sehingga tergambar kondisi zaman hari ini, kondisi objektif lembaga pendidikan Islam abad 21 dan merefleksi dan memberikan solusi konstruktif bagi caracara yang seharusnya dilakukan oleh LPTI di Indonesia. Oleh sebab itu, tujuan penelitian ini akan menjelaskan tetang cara-cara yang mangkus untukmebangun pendidikan tinggsi Islam yang kompetitif untuk abad 21.

\section{METODE}

Untuk mendapatkan data yang valid, metode yang dipakai penelitian ini yaitu metode kajian pustaka dengan (1) membaca, mencatat dan menganalisis referensi-referensi yang relevan dengan permasalahan yang diajukan. (2) mengamati secara langsung pandangan para pakar tentang kondisi abad 21 dan pendapatnya dalam koteks pendidikan tinggi Islam dalam pertemuan-pertemuan ilmiah yang pada akhirnya menjadi data /informasi ilmiah bagi penulis. Sumber data dari dua orang informan kunci. (3) mendeskripsikan kedua metode dan menyimpukannya di atas sehingga menjadi pemikiran yang sistematis, logis, objektif, dan realistic tentang pendidikan tinggi Islam yang kompetitif di era globalisasi. 


\section{HASIL DAN PEMBAHASAN \\ Kondisi Pendidikan Tinggi Abad 21}

Wajah dunia abad 21, menurut Jacques Delors, mempunyai dua wajah yaitu (1) Menakutkan karena dapat mempercepat terjadi kemiskinan dan perasaan benci negara-negara miskin terhadap negara-negara kaya.Yang paling merasakan benar kondisi ini adalah negara-negara yang berada di belahan bumi bagian Selatan yang notabene kebanyakan manusianya beragama Islam. (2) wajah dunia abad 21 dapat juga membahagiakan, terutama bagi negara-negara maju, kuat dan berkua-litas karena tingkat pendidikan dan kualitas hidup mereka lebih baik. Hal ini dirasakan oleh masyarakat manusia yang berada di negara-negara belahan bumi bagian Utara, yaitu negara-negara Eropa, Amerika, dsb. Walaupun sumber daya alam mereka kurang menjanjikan, tetapi sumber daya manusia sangat mendukung untuk meraih kebahagiaan di dunia (Jacques Delors, 1998).

Kedua wajah dunia di atas mengharuskan lembaga-lembaga pendidikan tinggi Islam menyesuaikan paradigmanya, standarisasinya, baik visi, misi, strategi pengembangan ilmunya, perkulihannya dan penelitianpenelitiannya. Pendidikan tinggi di negara-negara maju mengalami perubahan dari pemakai ilmu (scientific university) menjadi produser ilmu (research university), dari pendidikan tinggi teaching menjadi pendidikan tinggi research. Hal ini terjadi karena kebutuhan masyarakat dunia berubah, gaya hidup masyarakat menjadi instan, pragmatik, dan semakin berkualitas di negara maju (umumnya negara-negara belahan bumi utara, seperti Amerika, Inggris, dsb) serta semakin miskin di negara-negara berkembang, umumnya di negara-negara belahan bumi selatan, seperti negara-negara di Asia Tengah, Timur Tengah, Asia Tenggara, dsb yang notabene penduduknya mayoritas muslim.

Pengamatan penulis terhadap beberapa program studi yang ada di perguruan tinggi Islam yang dahulunya menjadi kebanggaan, primadona, dan menjadi ciri pendidikan Islam, pada masa kini sangat terbalik (terbalik bakul), tidak lagi diminati masyarakat untuk masuk ke dalamnya. Beberapa fakultas dan program studinya yang ada pada perguruan tinggi Islam tidak lagi layak jual karena tidak menjanjikan kehidupan dunia nyata yang layak baginya. Untuk apa mereka masuk ke situ jika tidak jadi apa-apa dan tidak menjanjikan lapangan kerja sebagaimana program studi yang lainnya. Paradigma masyarakat melihat program studi sudah banyak pilihan yang pada akhirnya masyarakat memilih yang menjanjikan kehidupan yang layak (walaupun sangat instan dan sementara), dan yang berstandar mutu di aras nasional, internasional dan bergengsi.

Akhir-akhir ini lembaga pendidikan tinggi Islam lebih suka bermain pada pembangunan pisik material daripada program akademiknya. Misalnya jika diban-dingkan gedung lembaga pendidikan tinggi Islam di Indonesia jauh lebih wah dibandingkan dengan Lembaga pendidikan tinggi di Sudan atau Somalia (Wamendiknas,26-8-2013). Tetapi dari segi program dan kegiatan akademik mereka jauh menggungguli Indonesia.Program akademik mereka sudah mendunia dan diakui dunia.Sementera kita, gedungnya yang mewah tapi ranking pendidikan tingginya masih rendah. Ranking LPTIN berdasarkan data dari Badan Akreditasi Nasional Perguruan Tinggi yaitu 8,1 \% berpredikat A, 46,8\% =B, 25,7\% = C dan 19,4\%=belum terakreditasi. Tambah parah lagi rangkin mutu PTI Swasta yaitu 31,7\% belum terakreditasi, 26,8\% =B, $39,8 \%=\mathrm{C}$ dan hanya 1,7\% terakreditasi A (Website Diktis,2 10-2013).

Sementara itu, regulasi yang ada, seperti Undang-Undang No. 20 tahun 2003 tentang Sistem Pendidikan Nasional, Undang-Undang no. 14 tahun 2005 tentang Guru dan Dosen, Peraturan Pemerintah No. 19 tahun 2003 tentang Standar Nasional Pendidikan. Semuanya mengacu kepada standar mutu akademik yaitu standar ideal, standar kompetensi, standar isi, standar proses, dan evaluasi. Dengan demikian, pengelolan pendidikan tinggi Islam tidak hanya didasarkan pada sarana yang mewah, tetapi pada programprogram akademiknya yang bermutu, yang dapat dilihat dari standar kompetensinya, standar isi, standar proses dan kerjasama antar lembaga pendidikan, dan sumber daya yang bermutu.

Pendidikan Islam harus dapat membaca tanda-tanda zaman dengan menyiapkan diri memasuki wilayah standar mutu yang berkembangn di aras nasional dan internasional. Lembaga Pendidikan Islam yang tradisional; tidak berstandar mutu akan menjadi lembaga kelas 2 yang cepat atau lambat akan ditinggalkan oleh pelanggannya. Jika ingin eksis, unjuk kerja lembaga pendidikan tinggi Islam harus masuk ke wilayah standar mutu, profesional, jujur, dan tranparansi tentang program dan sumber daya yang ada. Namun pada kenyataannya, sumber daya manusia yag di LPTI bekerja tidak berada dalam sistem,misalnya seorang ketua jurusan bekerja tanpa mengetahui program mana yang akan dicapainya yang dengan dengan visi-misi perguruan tingginya. (Observasi dan diskusi kinerja stap LPTI, 2019).

Menyikapi paparan di atas, setidaknya ada 2 tantangan yang dihadapi oleh LPTI masa kini, antara lain: (1) Peranan Pemerintah RI yang terus menancapkan kukunya sehingga memasuki aras-aras teknis membuat pendidikan tinggi Islam tidak banyak berbuat, tidak otonom dalam memanfaatkan dana, dan pada akhirnya perguruan tinggi yang idam-idamkan oleh visi dan misinya mengalami kesulitan untuk dicapai. 
(2) Di segi lain, sistem anggaran, regulasi yang ada dan administrasi yang diterapkan Pemerintah RI ini turut menjadi tantangan atau hambatan bagi majunya pendidikan tinggi Islam dan juga Pendidikan Nasional. Menurut Prof. Dr.Irwan Prayitno, M.Si (juga Gubernur Sumatera Barat) dalam orasi ilmiah (7-9-2013) mengatakan bahwa"Pemerintah Daerah mendukung semua program pendidikan tinggi Islam asalkan sesuai dengan regulasi yang ada", Di sini berarti terdapat peraturan Pemerintah yang dapat menghalangi pemerintah daerah untuk membantu lembaga pendidikan yang vertikal, dalam hal ini perguruan tinggi Islam". Pendapatnya ini menggambarkan bahwa regulasi yang ada menjadi hambatan bagi kerjasama Pemerintah daerah dengan perguruan tinggi yang notabene berada di wilayah kekuasaan pemerintah daerah. (3) Produktivitas yang rendah, keterbatasan daya tampung, keterbatasan kemampuan berkembang, kepincangan layanan akademik, dan distribusi yang tidak seimbang dalam pengembangan ilmunya membuat lembaga pendidikan Islam harus mengevaluasi dirinya kembali agar lembaga ini menjadi lembaga tempat masyarakat belajar. Sebagaimana yang dideklarasikan UNESCO, yaitu belajar untuk semua, ilmu untuk pengetahuan, ilmu untuk perdamaian dan pembangunan, ilmu dalam masyarakat dan untuk masyarakat (Washinton, 2001:267). Solusi dari ini semua adalah agar perguruan tinggi Islam melalukan perubahan (change) yaitu menjadi agen perubahan yang mencerdaskan dalam membentuk kualitas anak bangsa menjadi sarjana Islam yang profesional, berakhlak mulia, kompetitif, dan berkarakter kebangsaan.

\section{Lembaga Pendidikan Berstandar X Non Standar}

Lembaga pendidikan tinggi di negara maju telah memberlakukan pendidikan dengan standar mutu yang diakui dunia, misalnya International Standarzation for Organization (ISO) 9000, British Standard (BS 5750), Standar Asean University Network (AUN), dsb.Masing-masing standar ini mempunyai fungsi dan lingkup akuntabilitas tersendiri, dan di Indonesia ada Standar Pendidikan Nasional (SPN) dan Badan Akreditasi Nasional Perguruan Tinggi (BAN PT).Dengan demikian, layanan Pendidikan Tinggi harus memenuhi standar perundangan dan peraturan yang berlaku di tingkat regional, nasional, dan internasional sehingga produknya diterima oleh masyarakat Indonesia dan dunia. Hal ini berarti lembaga pendidikan tinggi yang tidak jelas standar mutu produknya sedikit demi sedikit akan tersisih oleh yang berstandar mutu.

Dalam konteks ini, kualitas lembaga pendidikan tinggi Islam mengalami krisis kepercayaan masyarakatnya, karena masyarakat memberlakukan pendidikan tinggi sebagai layaknya corporate, perusahaan, yang harus menjamin mutunya dan melayani pelanggannya dengan cepat, tepat, transparan, jujur, dan memuaskan. Maka pada masa sekarang, suatu layanan Pendidikan Tinggi dikatakan terbaik dan terjamin mutunya, jika memenuhi kriteria (1) transparan dan jujur dalam membangun mutunya sehingga para pelanggannya mengetahui secara jelas potensi sumberdaya yang ada, proses kerja dan mengembangannya, alatalat pendukungnya, dan hasil (outcome) yang akan diproduk nya. (2) pelayanan pendidikannya mampu mengubah mahasiswa menjadi sarjana yang memiliki kompetensi dalam bidang ilmu yang ditekuninya dengan jangka waktu 4 tahun (8 semester), (3) bermoral terpuji, (4) lulusannya mudah mendapat pekerjaan, dan (5) mampu bersaing di aras regional, nasional, dan internasional, (6) memuaskan para pelanggannya (mahasiswa dan masyarakat) dan stakeholders (UI,2008), serta (7) dapat mensejahterakan tenaga akademiknya (dosen dan karyawan nya).

Tuntutan yang demikian itu membawa akibat kepada program-program studi yang tidak mau berubah dan tidak berstandar mutu akan ditinggalkan oleh para pelanggannya dan akan mati suri. Pengamatan dan pengalaman penulis melihat beberapa program studi yang ada di pendidikan tinggi Islam yang dahulu menjadi kebanggaan dan ciri pendidikan tinggi Islam, kini mulai redup dan cendrung tidak diminati oleh sebagian masyarakat karena salah asuh, kalah saing dan tidak mau berubah, baik perencanaannya maupun pelaksanaannya. Oleh sebab itu, perubahan ke arah standar mutu dan pengelolaan manajemen yang bermutu serta berdaya saing menjadi solusi yang tepat untuk meyakinkan masyarakat terhadap lembaga pendidikan Islam.

Lembaga pendidikan tinggi Islam tidak bisa lagi berbicara kejayaan masa lalu (pada masa klasik) tanpa ada upaya membangun kejayaan masa kini. Lalu bagaimana membangun mutu lembaga pendidikan Islam masa kini, abad 21 ?. Jawabnya dengan menjadikan lembaga pendidikan Islam yang bermutu yaitu (1) mampumembentuk mahasiswa menjadi sarjana yang unggul dan pada waktu yang tepat (4 tahun) dengan IPK minimal rata-rata 3,1 sebanyak minimal $51 \%$; tidak boleh di bawah itu.(2) bermoral terpuji, (3) lulusannya mudah mendapat pekerjaan, dan (4) mampu bersaing di aras regional, nasional, dan internasional, (5) memuaskan para pelanggannya (maha siswa dan masyarakat) dan stakeholders.

\section{Research University $X$ Learning University}

Sebagaimana kita ketahui bahwa abad 21 adalah abad globalisasi, yaitu abad interdependensi, persaingan, dan kemajuan ilmu dan teknologi informasi dan komunikasi. Interdepensi menggambarkan 
bahwa sesuatu yang terjadi pada suatu negara akan berhubungan dan berakibat pada negara lain dalam waktu yang relatif singkat. Keadaan ini membutuhkan perubahan paradigma dalam pengelolaan pendidikan tinggi Islam. Jika tidak, pendidikan Islam akan mengalami kesulitan menghadapi tantangan abad 21 yang memberlakukan pendidikan ibarat corporate (perusahan) yang harus mampu menjamin mutu dan layanan terbaik bagi para pelanggannya. Kemajuan ilmu dan teknologi, di satu segi memang membawa kebahagiaan, terutama bagi negara-negara maju yang mendasari pembangunan atas teknologi informasi dan tranfortasi. Namun di segi lain, kemajuannya dapat membawa kesengsaraan bahkan mempercepat kemusnahan kehidupan bagi masyarakat miskin dan negara-negara miskin.

Deklarasi UNESCO tentang visi dan aksi pendidikan tinggi abad 21 menegaskan bahwa misi dan nilai pokok pendidikan tinggi adalah memberikan kontribusi kepada pembangunan yang berkelanjutan dan pengembangan masyarakat secara menyeluruh. Dalam konteks ini, pendidikan tinggi harus mendidik mahasiswa dan warganegara untuk memenuhi kebutuhan seluruh sektor aktivitas manusia dengan menawarkan kualifikasi yang relevan, mata kuliah dirancang dengan mengkombinasikan antar disiplin ilmu, dan memajukan ilmu dan teknologi melalui riset yang tidak hanya to know, tetapi juga to predict, to do, to change yang dapat merubah kehidupan masyarakat dari tidak tahu menjadi tahu, dari penggangguran menjadi menjadapt pekerjaan, dari miskin menjadi kaya, dst (Kemenag,2008:12).

Paparan di atas menganjurkan agar mutu lembaga pendidikan tinggi Islam diakui dan dinikmati masyarakat, maka pendidikan tinggi merubah wajahnya dari perguruan tinggi pemakai ilmu (learning university) menjadi lembaga yang memproduksi ilmu dan teknologi (research university). Ide ini tidak mulukmuluk jika dimulai dari cara-cara yang sederhana, misalnya cara kuliah mahasiswa mengharuskan melalukan observasi lapangan dan teoretik dari objek yang berkembang sehingga menjadi suatu kajian yang berwawasan riset.

Pendidikan Islam harus dapat membaca tanda-tanda zaman dengan menyiapkan diri memasuki wilayah standar mutu yang berkembang di aras nasional dan interna sional. Lembaga Pendidikan Islam yang tradisional; tidak berstandar mutu akan menjadi lembaga kelas 2 yang cepat atau lambat akan ditinggalkan oleh pelanggannya. Jika ingin eksis, unjuk kerja lembaga pendidikan tinggi Islam harus masuk ke wilayah standar mutu, profesional, jujur, dan transparansi tentang program dan sumber daya yang ada.

Menyikapi paparan di atas, tantangan yang dihadapi oleh lembaga pendidikan Islam, antara lain, (1) peranan Pemerintah RI yang terus menancapkan kukunya sehingga memasuki aras-aras teknis membuat pendidikan tinggi Islam tidak banyak berbuat, tidak otonom dalam memanfaatkan dana, dan pada akhirnya perguruan tinggi yang diidam-idamkan oleh visi dan misinya mengalami kesulitan untuk dicapai. Sistem anggaran dan administrasi yang diterapkan Pemerintah RI ini turut menjadi tantangan atau hambatan bagi majunya Pendidikan Nasional dan lembaga pendidkan tinggi Islam yang secara organisasi merupakan lembaga vertikal kepada Kemenag RI. (2) Produktivitas yang rendah, keterbatasan daya tampung, keterbatasan kemampuan ber kembang, kepincangan layanan akademik, dan distribusi yang tidak seimbang dalam pengembangan ilmunya membuat lembaga pendidikan Islam harus mengevaluasi dirinya kembali agar lembaga ini menjadi lembaga tempat masyarakat belajar. Sebagaimana yang dideklarasikan UNESCO, yaitu belajar untuk semua, ilmu untuk pengetahuan, ilmu untuk perda-maian dan pembangunan, ilmu dalam masyarakat dan untuk masyarakat (Washinton,2001:267).

Perkuliahan di lembaga pendidikan tinggi Islam sudah selayaknya melalui pendekatan riset yang mempertemukan antara teori para pakar Islam, pakar barat dan fakta di lapangan. Dengan pendekatan ini mahasiswa dan sarjana perguruan tinggi Islam akan mendapat sumber pengetahuan yang lengkap, yaitu teori para pakar dan fakta-fakta yang terjadi di lapangan. Jika tidak demikian, mahasiswa hanya akan mendapatkan pengetahuan yang tidak jelas kegunaan; yang menurut Sadino (Pengusaha Kaya di Indonesia) bahwa perguruantinggi itu memberikan sampah-sampah kepada mahasis wanya karena teori yang diberikannya sudah lama dan tidak bisa dipakai dalam menyelesaikan kehidupannya masa depan. Ilmu itu untuk kesejahteraan manusia; bukan ilmu untuk ilmu.Oleh sebab itu, menjadi perguruan tinggi riset yang memproduksi ilmu adalah tuntutan zaman dan kebutuhan masyarakat abad kini.

\section{Paradigma Pengembangan Ilmu di Lembaga Pendidikan Tinggi Islam}

Jika pada abad-abad sebelumnya ilmu berkembang dalam tataran teoretik, ilmu untuk ilmu, ilmu seakan berdiri di puncak menara gading dan kurang menyentuh kehidupan riil manusia. Maka pada abad 21, ilmu memasuki aras teoretik dan pragmatik yang sangat maju. Ilmu tidak lagi bergerak di kawasan rasional dan teoretik saja, tetapi dalam kehidupan riil manusia.Dengan demikian, manfaat ilmu bukan untuk ilmu saja, tetapi untuk memecahkan masalah kehidupan manusia secara komprehensif dan terpadu. Lembaga pendidikan tinggi Islam sudah selayaknya menjadikan ilmu dan hasil-hasil risetnya untuk memecahkan 
masalah yang terjadi di masyarakat; bukan mengawang-awang tak tentu arah tujuannya dan apa yang akan dipecahkannya.

Dalam konteks ini, kebijakan Kementian Agama RI untuk mensinergikan antara riset dan pengabdian pada masyarakat adalah sangat tepat sehingga ilmu dan riset bukan sekedar to understand, to explain, dan to predict, tetapi juga to change of emancipatory, perubahan yang membebaskan. Walaupun pada prakteknya, skripsi, tesis dan disertasi mahasiswa di perguruan tinggi Islam masih berputar pada pengembangan ilmu untuk ilmu; dari buku ke buku yang tidak menyentuh secara riil kehidupan dan persoalan manusia hari ini dan akan datang. Oleh sebab itu, masalah-masalah yang ditelitinya tidak relevan dengan perkembangan ilmu abad kini dan tuntutan zamannya.Hasil-hasil penelitiannya hanya tersimpang dalam rak-rak perpustakaan yang tidak dikomunika- sikan ke dunia nyata. Sampai kapan paradigma pengembangan ilmu di perguruan tinggi Islam dilakukan sepertiu ini?.wallahu a'lam. Kebijakan ini belum dipahami dengan baik oleh lembaga pendidikan tinggi Islam di Indonesia.Buktinya masih banyak karya tulis ilmiah mahasiswa dan dosen yang metodologi risetnya tidak berparadigma masih berkeliaran di UIN, IAIN, dan STAIN.

Paradigma lembaga pendidikan tinggi Islam dalam pengembangan disiplin ilmu-ilmunya pada abad 21 haruslah identik dengan tuntutan abadnya. Hal ini berarti, ilmu-ilmu keislaman harus digunakan untuk memecahkan masalah kehidupan manusia, cara kerja ilmiah yang digunakan harus sesuai dengan anatomi dan masalah kehidupan yang mengacu kepada nilai-nilai dan kaidah kehidupan atau kebutuhan ummat manusia yang sangat kompleks. Hal ini berarti, integrasi "ilmu dan Islam" dan interdisiplinary berbagai disiplin ilmu keislaman dibutuhkan dalam kegiatan pelaksanaan tridarma di lembaga pendidikan tinggi Islam. Riset-riset lembaga pendidikan tinggi Islam harus mampu membuktikan kebenaran wahyu Al-Qur'an dan hadis SAW sebagai sumber inspirasi ilmu dan menerapkannya untuk pengetahuan, perdamaian dan pembangunan ummat.Lembaga pendidikan Islam jangan terjebak oleh ide-ide baru yang kelihatannya membawa kemajuan. Namun jika diperhatikan akan menghilangkan cirinya. Hal ini dapat membawa akibat kurang kharismatiknya lembaga pendidikan Islam di mata masyarakatnya.

Pada acara AICIS 11 tahun 2011 di Bangka Belitung dipaparkan tentang Islam di ruang publik menggambarkan masih banyak yang belum dapat dijawab, seakan ada gap yang tidak bersambung antara teks Al-Qur'an dan Hadis nabi SAW dengan kondisi riil masyarakat di ruang publik. Baik persoalan yang menyangkut kenegaraan, sosial kemasyarakatn, ekonomi, politik, dsb.(AICIS, 2011 dan Pandangan para Pakar Islam).Ini artinya, paradigma pengembangan ilmu di perguruan tinggi Islam masih berputar di antara teks dan pemikiran masa lalu.Paradigma pengembangan ilmu masih ilmu untuk ilmu; bukan ilmu untuk manusia yang secara langsung menyentuh kehidupan riil manusia.

Oleh sebab itu, yang harus dilakukan perguruan tinggi Islam antara lain, merubah paradigma pengembangan ilmu, masalah-masalah risetnya, strategi per-kuliahannya, manajemen akademiknya,dsb.Jika tidak berubah, maka ia akan kalah saing dengan perguruan tinggi lainnya. Berubah atau kalah.

\section{Peranan Bahasa Arab}

Lembaga pendidikan Islam di mana pun berada tidak dapat meninggalkan dan menyepelekan bahasa Arab sebagai mata kuliah, sebagai bahasa Al-Qur'an, hadis Nabi SAW, bahasa agama Islam dan dunia Islam. Oleh sebab itu, peran bahasa Arab sangat penting dan menjadi ciri lembaga pendidikan Islam. Memajukan pengajaran bahasa Arab merupakan cara yang efektif untuk pengembangan lembaga pendidikan Islam dan memainkan perannya di dunia. Fungsi-fungsi bahasa Arab bagi mahasiswa merupakan kebutuhanyang penting, karena ia telah menjadi bahasa agama, bahasa komunikasi resmi antar bangsa (PBB), bahasa dunia Islam, bahasa perdagangan, bahasa ekonomi dan perbangkan Islam, bahasa kebudayaan, bahasa ilmu pengetahuan dan teknologi, bahasa hukum, bahasa gaul, dsb.Oleh sebab itu, sejak dahulu sampai kini, hampir tidak ada negara dan perguruan tinggi di dunia ini, di negara-negara maju, yang tidak membuka jurusan atau program studi bahasa Arab atau kajian-kajian yang bernuansa bahasa dan peradaban Arab.

Berkembangnya secara pesat perekonomian, ilmu pengetahuan, peradaban, dan pergaulan masyarakat tutur Arab menyebabkan bahasa Arab tidak lagi berada pada wilayah Timur tengah saja, tetapi merambah ke penjuru dunia. Masyarakat dunia merasakan betapa pentingnya mempelajari bahasa Arab dan kajian-kajian Timur Tengah. Sejak dahulu sampai kini, bahasa Arab telah dipelajari oleh masyarakat dunia dan hampir tidak ada universitas di negara maju yang tidak membuka jurusan bahasa Arab, misalnya, di Barat, sejak abad XI, sebagian masyarakat Eropa telah mempelajari bahasa Arab, karena buku-buku ilmiah, seperti kedokteran, IPA, matematika,dll yang ada di Toledo, Seviila, dan Cordova, banyak bertulisan bahasa Arab, maka para raja, misalnya Ferederik II dan Alfonso X, menyuruh semua rakyatnya mempelajari bahasa Arab, karena mampu berbahasa Arab, pada saat itu, merupakan gengsi dan kebanggaan bagi sebagian masyarakat Eropa. 
Di Indonesia, misalnya ada UI,UGM,UNJ, IPB, UPI, USU, UM, PTAI, dsb. Di Universitas negaranegara Asean, Universitas Roma di Itali , Universitas Bologna, Roma, dan Slenna, universitas Oxford, Cambridge, London, Durham, Andrews, dsb di Ingris,di Kanada ada Universitas McGill dan Ottawa, di Australia, di Belanda ada Univesitas Leiden, Universitas Amsterdam, dsb. di Jerman ada universitas Heidenberg, Munchen, Berlin, dsb. di Rusia ada Universitas Moskow, Kharkov, dsb, di US ada Universitas Harvard, Calombia, California, dsb. Semuanya mempelajari dan menkaji bahasa Arab dengan sangat serius.Oleh sebab itu, lembaga pendidikan Islam di Indonesia harus serius memajukan bahasa Arab jika ingin disegani oleh lembaga pendidikan tinggi lainnya.

Menurut pengamatan penulis, sejak perguruan tinggi Islam, seperti UIN, IAIN, dan STAIN menjadi perguruan tinggi yang tebuka dengan program-program studi yang banyak, ada beberapa program studi yang dahulunya menjadi idola dan ciri perguruan tinggi Islam kini menjadi mengecil dan kurang diminati masyarakat karena mereka telah memiliki banyak pilihan. Jurusan bahasa Arab dan tafsir-hadis, pemikiran Islam, menjadi prodi yang kurang dipilih oleh calon mahasiswa karena mereka takut dengan matakuliah bahasa Arab dan lapangan kerja yang kurang berprospek, dsb.Oleh sebab itu wajar saja hal ini terjadi karena perguruan tinggi Islam tidak serius mengembang kannya dan melakukan program pemertahanannya. Para pemangku kebijakan di perguruan tinggi Islam lebih banyak bicara tentang pentingnya bahasa Arab tetapi sumber dana dan unjuk kerjanya untuk itu tidak ada. Kemenag RI sibuk dengan sejumlah program tetapi mana program pembinaan, pengembangan ilmu dan penelitian yang memberikan kesempatan bagi guru dan dosen bahasa Arab.Sangat minim sekali.Peranan bahasa Arab yang begitu penting bagi memahami ilmu-ilmu bahasa Arab dan Islam seakan hanya ada dalam ucapan bibir tapi tak ada dalam programnya.Aneh.

\section{SIMPULAN}

Di antara solusi permasalahan di atas adalah (1) harapan lembaga pendidikan tinggi Islam harus tetap bepegang teguh kepada landasan utamanya, Al-Qur'an dan Hadis, dan memperhatikan serta memperkuat pengajaran bahasa Arab yang dengannya lembaga pendidikan Islam harus mampu membuktikan akan kebenaran landasan itu dalam kehidupan manusia/masyarakat dan disamping (2) lembaga pendidikan Islam harus memasuki aras standar mutu yang resmi, seperti standar BAN PT, Standar AUN, dsb. Jika tidak, produk lembaga pendidikan tinggi Islam akan kalah bersaing dan melahirkan banyak penggangguran yang akan menyengsarakan banyak kaum terpelajar akibat dari produk yang tidak bermutu. dan pada akhirnya (3) lembaga pendidikan Islam menjadikan dirinya sebagai pendidikan tinggi riset yang bertujuan untuk merubah yang sebenarnya (research to cange of emancipartory). Hal ini dapat dilakukan dari cara-cara yang sederhana.

\section{REFERENSI}

Ainurrfiq Dawam, dkk, (2004), Manajemen Madrasah Berbasis Pesantren, Jakarta, Lista Fariska Putra.

Amin Haedari, dkk, (2004) Masa Depan Pesantren, Jakarta, IRD Press.

Depag RI, (2008) Panduan Penelitian di PTAI, Jakarta, DepagRI.

Tim Dewan Redaksi, DIKTIS Kemenag RI,(2008), Gamang, Lembaga Pendidikan Islam Mengahadi Perubahan Sosial.

Fasli Jalal dan Dedi Supriyadi, (2016), Reformasi Pendidikan Dalam Konteks Otonomi Daerah Jakarta, Jakarta, Depdiknas.

Gordon Dryden and Dr.Jeannete Vos, (1996), The Learning Revolution, USA, The Learning Web, Hasan Langulung, Manusia dan Pendidikan, Bulan Bintang.

Irwan Prayitno, Orasi Ilmiah tgl 2-9-2013 di STAIN Batusangkar.

Jacques Delors, (1998), Pendidikan Untuk Abad XXI, UNESCO Publishing.

M. Yamin, (2009), Manajemen Mutu Kurikulum Pendidikan, Yogyakarta.

Syamsul Nizar, (2010), Isu-Isu Komtenporer Tentang Pendidikan Islam, Jakarta, Kalam Mulia.

Sunaryo Kartadinata, (2010), Isu-Isu Pendidikan Antara Harapan dan Kenyataan, Bandung, UPI Press.

Universitas Indonesia,(2018), Buku Pedoman Penjaminan Mutu, Jakarta, UI Press.

Wamendiknas, Orasi Ilmiah tgl.26-8-2013 di STAIN Batusangkar.

Washington, P, (2001), Universitas Yang Kudambakan, Jakarta, Diknas. 